\title{
Surface Catalysis Effects on Mitigation of Radio Frequency Blackout in Orbital Reentry
}

\author{
Yusuke Takahashi ${ }^{1}$, Naoya Enoki ${ }^{2}$, Hideto Takasawa ${ }^{3}$, and Nobuyuki Oshima ${ }^{4}$, \\ Hokkaido University, Kita 13 Nishi 8, Kita-ku, Sapporo, Hokkaido 060-8628, Japan
}

Keywords: Atmospheric reentry, Mitigation of radio frequency blackout, Surface catalysis effects, Electromagnetic waves in plasma

\begin{abstract}
Radio frequency (RF) blackout during atmospheric reentry leads to the cutoff of communication with ground stations and/or data-relay satellites. This causes significant problems during reentry, and thus, mitigation methods have been in high demand. In this study, we numerically demonstrate a novel method for mitigating the RF blackout using surface catalysis effects. Plasma flow behavior and electromagnetic wave propagation around a reentry vehicle were investigated in detail. The approach couples computational fluid dynamics and a frequency-dependent finite-difference time-domain method. The computations were performed with a massive parallelization technique using a large computer. The computed results were compared for cases imposing low and full catalysis conditions on a surface boundary. The investigation revealed that the surface catalysis effects reduce the RF blackout. Atomic species, dissociated across a shock wave formed in front of the vehicle, were recombined on the vehicle surface through surface catalysis. These molecules, flowing into a wake region at the vehicle's rear, caused recombinations of electrons, originally generated in the shock layer. Therefore, a decrease in electrons was observed in the wake region and a wake path, which allows the propagation of electromagnetic waves, was formed. This complicated behavior of the molecules and electrons, induced by the surface catalysis, resulted in mitigation of the RF blackout.
\end{abstract}

\section{Nomenclature}

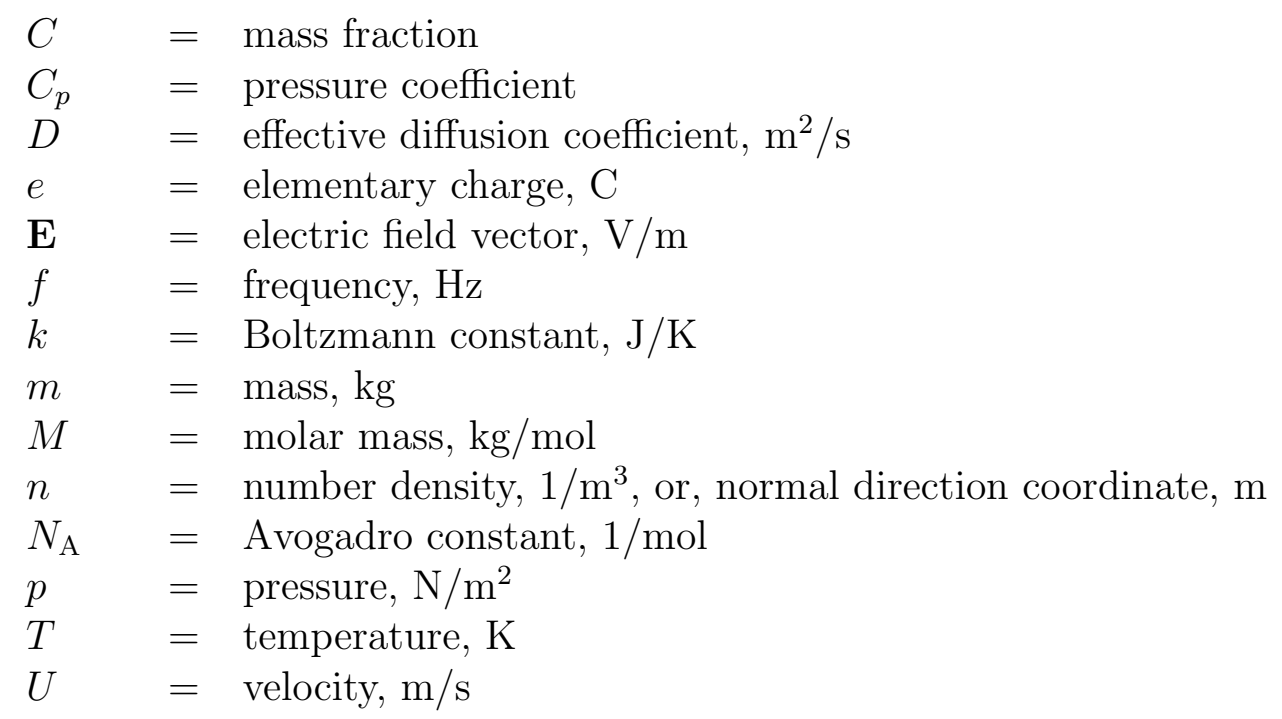

\footnotetext{
${ }^{1}$ Assistant Professor, Faculty of Engineering; ytakahashi@eng.hokudai.ac.jp.

${ }^{2}$ Graduate Student, Graduate School of Engineering.

${ }^{3}$ Graduate Student, Graduate School of Engineering.

${ }^{4}$ Professor, Faculty of Engineering.
} 


$$
\begin{array}{lll}
\gamma & =\text { catalytic recombination coefficient } \\
\varepsilon_{0} & =\text { permittivity in free space, } \mathrm{F} / \mathrm{m} \\
\rho & =\text { density, } \mathrm{kg} / \mathrm{m}^{3}
\end{array}
$$

$\begin{array}{lll}\text { Subscripts } & \\ \mathrm{e} & = & \text { electron } \\ \mathrm{s} & = & \text { species } \\ \mathrm{fs} & = & \text { free space } \\ \mathrm{w} & = & \text { wall } \\ \infty & = & \text { freestream }\end{array}$

\section{Introduction}

Radio frequency ( $\mathrm{RF}$ ) blackout and the aerodynamic heating problem during the entry, descent, and landing (EDL) phases of orbital and superorbital reentries are critically important issues. Due to the high speed of reentry into the atmosphere (faster than $7.8 \mathrm{~km} / \mathrm{s}$ ), a strong shock wave forms in front of the reentry vehicle. This shock waves dissociates and ionizes the gas, forming plasma that surrounds the vehicle surface. Depending on the frequency, the electromagnetic waves used for telecommunication are generally reflected and strongly attenuated by electrons exceeding the number density of the criterion value Hence, the RF blackout occurs with the development of a sufficiently ionized plasma caused by the strong shock wave. This leads to the cutoff of communication between the reentry vehicle and the ground station and/or data-relay satellites. Several problems in executing a reentry mission are caused by the RF blackout. When telecommunication with the ground station becomes impossible, it is difficult to track the location of the reentry vehicle, which can significantly increase the uncertainty in the prediction of the landing site and the cost of recovery. Additionally, in-flight data transmitted to the ground during reentry is blocked by the RF blackout and lost during for the duration of the blackout. These are significant problems for safe and efficient missions that include an EDL phase.

It is important to reduce the severity of the RF blackout for future reentry missions. Thus far, several techniques for mitigating the RF blackout have been proposed, including the use of lasers, magnetic fields, and electrophilic substances [1-3]. Kim et al. [4] reported that the application of an electromagnetic $\mathbf{E} \times \mathbf{B}$ layer to an antenna can control the plasma density and reduce RF blackouts. Belov et al. [5] experimentally investigated an aerodynamic shaping technique to mitigate RF blackouts by mounting slender nose-cone probes ahead of a bluntnosed vehicle. Takahashi et al. [6] suggested that an inflatable vehicle could passively reduce RF blackouts with data-relay satellites during atmospheric reentry because of its low-ballistic flight coefficient.

Jung et al. [7] found that surface catalysis effects may reduce the electron density around a reentry vehicle based on computational fluid dynamics (CFD) and computational electromagnetics (CEM) simulations [8]. This can lead to mitigation of the RF blackout. Additional shapes and active control devices are not required for this method. Therefore, it can contribute to the progress of safe and efficient reentry missions. However, surface catalysis generally increases the heating rate on the vehicle surface due to the release of thermal energy from recombination reactions. It is therefore necessary to optimize the surface catalysis, 
in order to balance both the mitigation of the RF blackout and decreases in aerodynamic heating. In addition, the mechanism of the mitigation is not clarified.

Further research into surface catalysis effects is required in order to understand how it mitigates the RF blackout. Detailed investigations over a wide range of surface catalytic conditions are still necessary. In this study, we investigate the mechanism of the surface catalysis effects and present a numerical demonstration of the mitigation. This is numerically performed by a predictive approach, combining CFD and CEM techniques based on highperformance computing.

\section{Reentry Capsule}

The atmospheric reentry demonstrator (ARD) [9] of the European Space Agency (ESA) was chosen as the object of analysis. This capsule was launched by the Ariane-5 V503 rocket on October 21, 1998. During the reentry phase, the ESA ARD continued to communicate with the tracking and data relay satellite (TDRS) and the global positioning system (GPS) satellites, despite the occurrence of the RF blackout and plasma attenuation. This reentry flight provided a good example for the investigation of the effects of surface catalysis on RF blackout mitigation.

The shape of the ESA ARD is shown in Fig. 1. The reentry capsule was the same shape as an Apollo command module, scaled down $70 \%$. This is a typical blunt-body capsule shape. The base diameter and nose radius of the front heat shield side were $2800 \mathrm{~mm}$ and $3360 \mathrm{~mm}$, respectively. The half-angle for the rear was $33^{\circ}$. It should be noted that an ablator material for the thermal protection system was applied to the forebody.

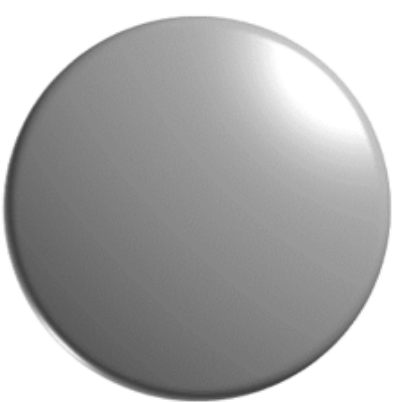

Front side

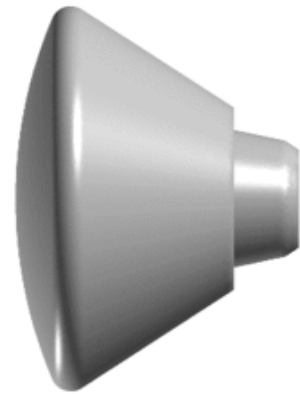

Lateral side

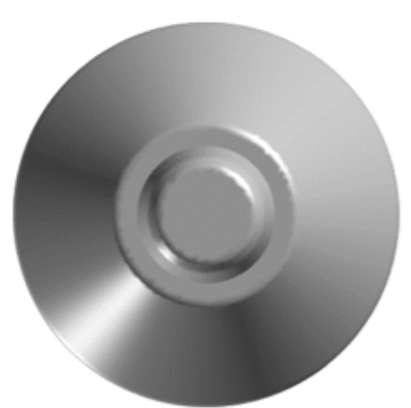

Rear side

Figure 1: Shape of ESA ARD.

The ESA ARD was separated from the rocket at an altitude of $218 \mathrm{~km}$ and reached its apogee at an altitude of $830 \mathrm{~km}$. The reentry capsule then started to reenter the Earth's atmosphere. The ESA ARD started its recovery sequence after deceleration due to the aerodynamic force in flight, and finally, splashed down in the Pacific Ocean. Figure 2 shows the reentry trajectory of the capsule. During reentry, the capsule's position, velocity, and altitude, reconstructed by acceleration measurements, were obtained using an onboard inertial navigation system and GPS receiver. The reentry velocity at an altitude of $120 \mathrm{~km}$ was approximately $7452 \mathrm{~m} / \mathrm{s}$. The ESA ARD was expected to be surrounded by a reentry 
plasma, due to the hypersonic strong shock layer. The reentry capsule's terminal velocity at splashdown was approximately $6.7 \mathrm{~m} / \mathrm{s}$. The ESA ARD employed dedicated skin antennae for a telemetry link and telecommunication with the TDRS. The link frequencies were approximately $2.267 \mathrm{GHz}$. No RF blackout for the TDRS link was observed. However strong plasma attenuation at the signal was measured from an altitude of $86 \mathrm{~km}$ to $44 \mathrm{~km}$. However, GPS telecommunications were completely cut off during the RF blackout. This is because the link frequency of GPS is lower than that of the TDRS telecommunication.

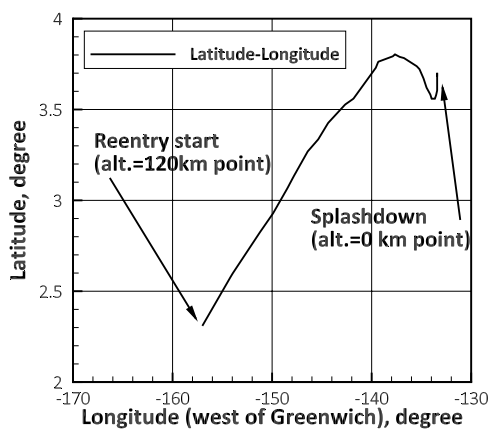

(a) Lattitude-Longitude.

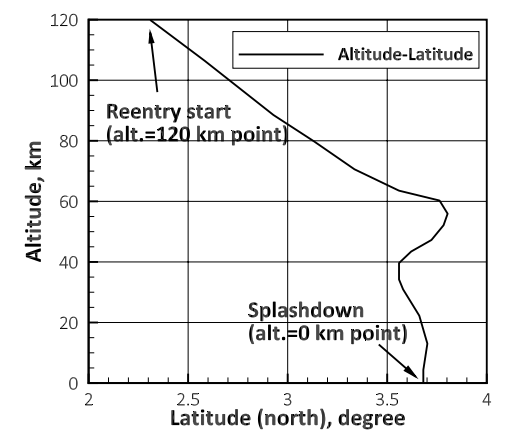

(b) Altitude-Latitude.

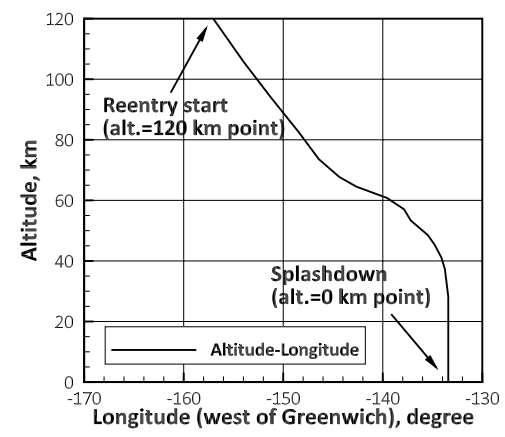

(c) Altitude-Longitude.

Figure 2: Trajectory of ESA ARD.

\section{Numerical Model}

In this section, we briefly explain the physical and numerical models used to simulate the plasma flow field and electromagnetic waves analyses. The governing equations and physical models for these simulations closely follow those used in the study by Takahashi [8]. Detailed descriptions of the models are presented in this reference.

\subsection{Plasma Flow}

The numerical models employed in the present study, which are described below, were implemented on a high-enthalpy flow solver, RG-FaSTAR [8]. This software incorporated real gas effects and thermochemical nonequilibrium; it is a version of the fast, unstructured CFD code "FaSTAR" [10], originally developed by JAXA.

For the numerical model, we assumed that the plasma flow was laminar, steady and that the continuum approximation applied throughout the modeled flow field. Thermochemical nonequilibrium was accounted for using Park's two-temperature model which models both a translational-rotational temperature and a vibrational-electron temperature. The governing equations of the flow field included the total mass, momentum, total energy, species mass, and vibrational-electron energy conservation, in addition to the equation of state.

For modeling chemical nonequilibrium in high-temperature air, the gas was assumed to consist of 11 chemical species: $\mathrm{N}_{2}, \mathrm{O}_{2}, \mathrm{NO}, \mathrm{N}_{2}^{+}, \mathrm{O}_{2}^{+}, \mathrm{NO}^{+}, \mathrm{N}, \mathrm{O}, \mathrm{N}^{+}, \mathrm{O}^{+}$, and $\mathrm{e}^{-}$. We assumed the occurrence of 49 reactions listed in Table 1. The mass production rates were calculated using both the forward and backward reaction rates. The forward reaction rate coefficients were obtained from Park's work [11], and the backward reaction rate was evaluated using the corresponding equilibrium constant $[12,13]$. To account for the thermal nonequilibrium flow, 
Table 1: Chemical reactions [11]

\begin{tabular}{|c|c|c|c|}
\hline$\overline{c r}$ & Forward & & "Backward \\
\hline $1-10$ & $\mathrm{~N}_{2}+M$ & $\rightleftharpoons$ & $\mathrm{N}+\mathrm{N}+M$ \\
\hline 11 & $\mathrm{~N}_{2}+\mathrm{e}^{-}$ & $\rightleftharpoons$ & $\mathrm{N}+\mathrm{N}+\mathrm{e}^{-}$ \\
\hline $12-21$ & $\mathrm{O}_{2}+M$ & $\rightleftharpoons$ & $\mathrm{O}+\mathrm{O}+M$ \\
\hline $22-31$ & $\mathrm{NO}+M$ & $\rightleftharpoons$ & $\mathrm{N}+\mathrm{O}+M$ \\
\hline 32 & $\mathrm{NO}+\mathrm{O}$ & $\rightleftharpoons$ & $\mathrm{N}+\mathrm{O}_{2}$ \\
\hline 33 & $\mathrm{~N}_{2}+\mathrm{O}$ & $\rightleftharpoons$ & $\mathrm{NO}+\mathrm{N}$ \\
\hline 34 & $\mathrm{~N}+\mathrm{N}$ & $\rightleftharpoons$ & $\mathrm{N}_{2}^{+}+\mathrm{e}^{-}$ \\
\hline 35 & $\mathrm{O}+\mathrm{O}$ & $\rightleftharpoons$ & $\mathrm{O}_{2}^{+}+\mathrm{e}^{-}$ \\
\hline 36 & $\mathrm{~N}+\mathrm{O}$ & $\rightleftharpoons$ & $\mathrm{NO}^{+}+\mathrm{e}^{-}$ \\
\hline 37 & $\mathrm{~N}+\mathrm{e}^{-}$ & $\rightleftharpoons$ & $\mathrm{N}^{+}+\mathrm{e}^{-}+\mathrm{e}^{-}$ \\
\hline 38 & $\mathrm{O}+\mathrm{e}^{-}$ & $\rightleftharpoons$ & $\mathrm{O}^{+}+\mathrm{e}^{-}+\mathrm{e}^{-}$ \\
\hline 39 & $\mathrm{NO}^{+}+\mathrm{O}$ & $\rightleftharpoons$ & $\mathrm{N}^{+}+\mathrm{O}_{2}$ \\
\hline 40 & $\mathrm{O}_{2}^{+}+\mathrm{N}$ & $\rightleftharpoons$ & $\mathrm{N}^{+}+\mathrm{O}_{2}$ \\
\hline 41 & $\mathrm{O}^{+}+\mathrm{NO}$ & $\rightleftharpoons$ & $\mathrm{N}^{+}+\mathrm{O}_{2}$ \\
\hline 42 & $\mathrm{O}_{2}^{+}+\mathrm{N}_{2}$ & $\rightleftharpoons$ & $\mathrm{N}_{2}^{+}+\mathrm{O}_{2}$ \\
\hline 43 & $\mathrm{O}_{2}^{+}+\mathrm{O}$ & $\rightleftharpoons$ & $\mathrm{O}^{+}+\mathrm{O}_{2}$ \\
\hline 44 & $\mathrm{NO}^{+}+\mathrm{N}$ & $\rightleftharpoons$ & $\mathrm{O}^{+}+\mathrm{N}_{2}$ \\
\hline 45 & $\mathrm{NO}^{+}+\mathrm{O}_{2}$ & $\rightleftharpoons$ & $\mathrm{O}_{2}^{+}+\mathrm{NO}$ \\
\hline 46 & $\mathrm{NO}^{+}+\mathrm{O}$ & $\rightleftharpoons$ & $\mathrm{O}_{2}^{+}+\mathrm{N}$ \\
\hline 47 & $\mathrm{O}^{+}+\mathrm{N}_{2}$ & $\rightleftharpoons$ & $\mathrm{N}_{2}^{+}+\mathrm{O}$ \\
\hline 48 & $\mathrm{NO}^{+}+\mathrm{N}$ & $\rightleftharpoons$ & $\mathrm{N}_{2}^{+}+\mathrm{O}$ \\
\hline 49 & $\mathrm{~N}_{2}+\mathrm{N}^{+}$ & $\rightleftharpoons$ & $\mathrm{N}_{2}^{+}+\mathrm{N}$ \\
\hline
\end{tabular}

$M=\mathrm{N}_{2}, \mathrm{O}_{2}, \mathrm{NO}, \mathrm{N}_{2}^{+}, \mathrm{O}_{2}^{+}, \mathrm{NO}^{+}, \mathrm{N}, \mathrm{O}, \mathrm{N}^{+}, \mathrm{O}^{+}$

the analysis included energy transfer between internal energy modes: translation-vibration, translation-electron, rotation-vibration, and rotation-electron.

Transport properties such as viscosity, thermal conductivity, and binary diffusion coefficients for a mixed gas were evaluated using Yos' formula [14]. This model is based on the first-order Chapman-Enskog approximation [15]. Collision cross-sections were obtained from Gupta [13] and Fertig et al. [16,17]. The effective diffusion coefficients are expressed using the formula developed by Curtiss and Hirschfelder [18]. In addition, an ambipolar diffusion was assumed for the ionized species and electrons.

The governing equations for the flow field, including the physical models mentioned above, were solved using a cell-centered finite volume approach. Evaluation of the advection fluxes across cell interface in the equations was performed by the AUSM+up2 scheme [19], using the MUSCL interpolation method to maintain high spatial accuracy. The van Leer limiter was used as a slope limiter function of the advection scheme. The viscous fluxes were calculated by obtaining an averaged value between gradients of neighboring computational cells. The weighted Green-Gauss method was adopted for calculating spatial gradients of the flow properties. Time integration was performed using an implicit time-marching approach. The governing equation system was transformed into the delta form, and the solution was updated at each time step. The matrix solver for the governing equation system was the lower-upper 
symmetric Gauss-Seidel (LU-SGS) method [20] coupled with the point-implicit method [21] for stable computation of the source term.

In the plasma flow solver, for massive parallel computation on a high-performance computer, the message-passing interface technique with a domain partition approach was introduced. The computations were performed on the $\mathrm{K}$ computer of the Riken Center for Computational Science (R-CCS).

\subsection{Calculation Conditions}

The computational domain containing boundary conditions for the plasma flow simulation is shown in Figure 3. The boundaries were composed of the following three parts: the inflow

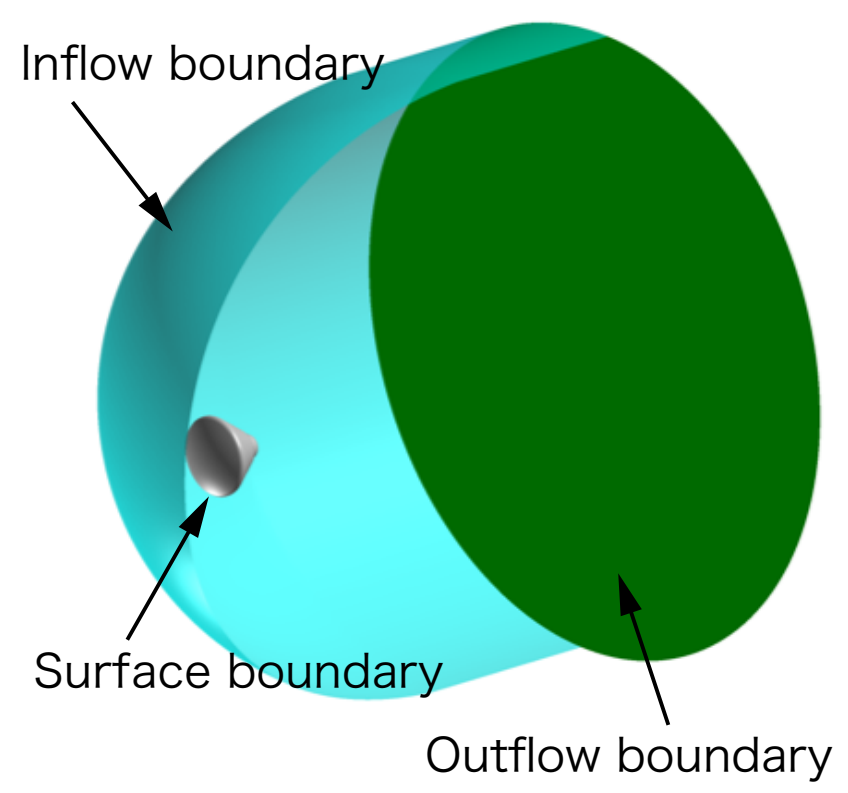

Figure 3: Computational domain and boundary conditions for plasma flow field simulation.

boundary, outflow boundary, and surface boundary on the capsule surface. At the inflow, the freestream conditions based on the reentry trajectory reported by Tran et al. [9] were applied. At the outflow, a gradient-free condition for all the flow variables was imposed. At the surface boundary, a non-slip condition for the velocity was imposed. There was also a condition excluding a pressure gradient normal to the surface. The surface temperature $T_{\mathrm{w}}$ was fixed at $300 \mathrm{~K}$ as a cooling wall condition. The surface catalysis, i.e., the finite catalytic condition, was described as follows:

$$
\rho D_{s} \frac{\partial C_{s}}{\partial n}=\gamma \sqrt{\frac{k N_{\mathrm{A}} T_{\mathrm{w}}}{2 \pi M_{s}}} \rho_{s}
$$

where $\rho, D_{s}, C_{s}, M_{s}$, and $n$ are the density, the effective diffusion coefficient of species $s$, mass fraction, molar mass, and coordinate in the direction normal to the wall surface, respectively. In addition, $k$ and $N_{\mathrm{A}}$ are the Boltzmann constant and the Avogadro constant, respectively. The following two catalytic recombination reactions were considered:

$$
\begin{aligned}
& \mathrm{N}+\mathrm{N} \rightarrow \mathrm{N}_{2}, \\
& \mathrm{O}+\mathrm{O} \rightarrow \mathrm{O}_{2} .
\end{aligned}
$$


The catalytic recombination coefficient $\gamma$ of both reactions was set to a value between 0 and 1.

The freestream parameters used herein are listed in Table 2. The chemical composition of the freestream was assumed to be $0.765 \mathrm{~N}_{2}$ and $0.235 \mathrm{O}_{2}$ in mass fractions. Although these compositions differed slightly at higher altitudes, the difference did not significantly affect the surface catalytic effects. The angle of attack of the ESA ARD was approximately -20 degrees during reentry. The flow field considered was always in a hypersonic flow regime from the freestream Mach number. Because the global Knudsen number, based on the diameter of the front heat shield, was less than $10^{-3}$, it is reasonable to assume a continuum flow. The Reynolds number based on the same diameter was $10^{4}$ at a higher altitude and $10^{5}$ at a lower altitude, respectively.

Table 2: Freestream parameters along the ESA ARD reentry trajectory.

\begin{tabular}{c|ccccc}
\hline \hline $\begin{array}{c}\text { Altitude } \\
(\mathrm{km})\end{array}$ & $\begin{array}{c}\text { Velocity } \\
(\mathrm{m} / \mathrm{s})\end{array}$ & $\begin{array}{c}\text { Density } \\
\left(\mathrm{kg} / \mathrm{m}^{3}\right)\end{array}$ & $\begin{array}{c}\text { Temperature } \\
(\mathrm{K})\end{array}$ & $\begin{array}{c}\text { Angle of attack } \\
(\text { degrees })\end{array}$ & Mach number \\
\hline 85.0 & 7577 & $8.183 \times 10^{-6}$ & 191.0 & -20.0 & 27.4 \\
80.0 & 7609 & $1.853 \times 10^{-6}$ & 195.8 & -20.0 & 27.1 \\
75.0 & 7593 & $4.073 \times 10^{-5}$ & 201.7 & -19.2 & 26.7 \\
70.0 & 7542 & $8.828 \times 10^{-5}$ & 210.9 & -19.2 & 25.9 \\
65.8 & 7212 & $1.587 \times 10^{-4}$ & 224.5 & -20.0 & 24.0 \\
60.0 & 6105 & $3.403 \times 10^{-4}$ & 242.0 & -19.4 & 19.6 \\
51.5 & 4906 & $9.211 \times 10^{-4}$ & 266.1 & -20.0 & 15.0 \\
\hline \hline
\end{tabular}

An example of computational grids used in the plasma flow simulation is shown in Fig. 4. Almost all of the grids in the computational domain were composed of a tetrahedral mesh. However, triangular prism meshes were carefully installed in the shock layer to resolve shock waves in order to avoid a numerical instability called "Carbuncle" [22,23]. In addition, thin triangular prism meshes were also laminated to resolve the boundary layer near the capsule surface. The number of cells and nodes of computational grids are listed in Table 3.

Table 3: Number of computational cells and nodes at various altitudes for plasma flow simulation.

\begin{tabular}{c|cc}
\hline \hline Altitude $(\mathrm{km})$ & Number of cells & Number of nodes \\
\hline 85.0 & $5,436,384$ & $1,366,101$ \\
80.0 & $10,259,624$ & $2,193,130$ \\
75.0 & $25,879,726$ & $7,967,584$ \\
70.0 & $25,879,726$ & $7,967,584$ \\
65.8 & $25,886,808$ & $7,968,120$ \\
60.0 & $31,833,038$ & $9,537,598$ \\
51.5 & $31,833,038$ & $9,537,598$ \\
\hline
\end{tabular}




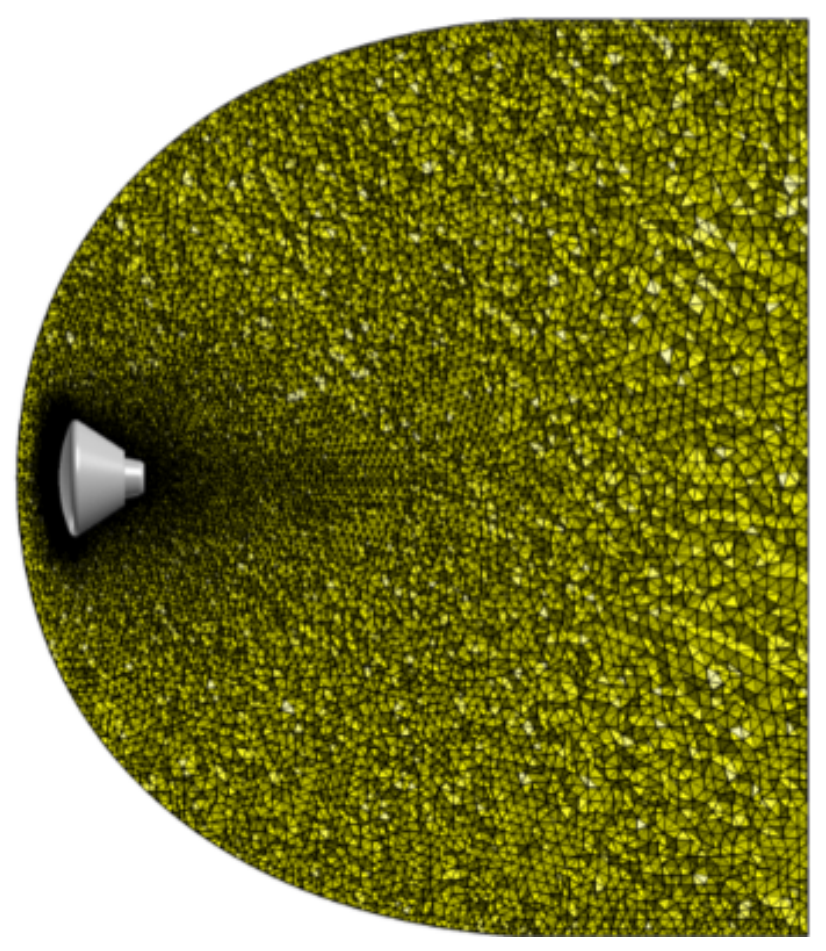

Figure 4: An example of computational grids around ESA ARD for plasma flow simulation.

\subsection{Electromagnetic Waves}

To evaluate surface catalysis effects on the RF blackout in communication between the reentry capsule and TDRS, the electromagnetic wave behavior was investigated using a numerical approach based upon Maxwell's equations. Reentry plasmas are generally a frequencydependent media. Therefore, dielectric constants and electrical conductivities of the plasma can vary over a frequency range. The finite-difference time-domain (FDTD) method assumes that these properties of the medium are independent of frequency. Hence, the FDTD method could lead to potentially incorrect results when applied to frequency-dependent media. In this study, the frequency-dependent finite-difference time-domain (FD2TD) method [24] was used to simulate electromagnetic waves in a frequency-dependent medium. To calculate the complex relative permittivity required in the FD2TD method, the first Drude dispersion was assumed.

The computational domain for the simulation of the electromagnetic waves in the FD2TD approach was set to rectangular dimensions of $12.5 \mathrm{~m}$ ( $x$-direction), $8.5 \mathrm{~m}$ (y-direction), and $6.0 \mathrm{~m}$ (z-direction), which included the ESA ARD inside the domain. The electric field and magnetic field vectors were staggered on the Yee's cell [25]. The entire computational grid was composed of hexahedral meshes as with the structured grids system. The computational grid nodes were set to 950 ( $x$-direction), 650 ( $y$-direction), and 460 (z-direction), i.e., a total of 284,050,000 nodes. The same computational grid system was used for the seven altitude cases listed in Table 2. The plasma angular frequency and electron collision frequency required for the FD2TD method were obtained from the computational results of the plasma flow simulations. The magnetic permeability was set to be the same as that of free space. In coupling with the plasma flow simulation, the flow field was frozen in the electromagnetic waves simulation (one-way coupling manner), because the electromagnetic waves are faster than the characteristic velocity of the flow field. As a boundary condition, Mur's first- 
order absorption boundary [26], i.e., far-field boundary, was imposed at all faces of the computational domain. However, a conduction boundary condition was imposed on the surface of the ESA ARD.

The telecommunication frequency was $2.267 \mathrm{GHz}$, which is the value used in telecommunication between the TDRS and ESA ARD during reentry. The waveform model was assumed to be a cosine function. The antenna for the telecommunication was assumed to be installed on the rear surface of the ESA ARD.

The physical and numerical models mentioned above were implemented in the electromagnetic waves simulation code "Arcflow/Arcwave". For fast computation and efficient allocation of memory, the simulation code was parallelized using the MPI and OpenMP techniques. A data transfer program between the electromagnetic waves and plasma flow simulation codes was also implemented.

\section{Results and Discussion}

\subsection{Parallel Efficiency in Computation}

Because the plasma flow model included many source term computations for the chemical reactions, a large computation resource was required. The computational cost of the electromagnetic waves analysis is significantly lower compared to that of the plasma flow. The R-CCS K computer was used for the presented simulations, which was one of the largest computers in the world. The $\mathrm{K}$ computer had 82,944 computer nodes, which include 8 cores per node. Thus, it was possible to run 663,552 parallel computations at capacity. Figure 5 shows the wall time profile of the plasma flow simulations for parallel computations using the $\mathrm{K}$ computer. The wall time in this figure was normalized by the standard computational cells of $10^{7}$ and the standard time step of 50,000 in the simulation. Good scalability was confirmed for less than 16,384 parallels, while the scalability deteriorated between 16,384 and 65,536 parallels. It was found that the parallel efficiency was not improved for a case of more than $10^{5}$ parallel computations. In the simulations, parallel computations from cores 2,048 to 8,192 were adopted according to the computational cases because they provided sufficient scalability.

\subsection{Comparison of Surface Pressure}

The ESA ARD used pressure sensors to measure the pressure profiles on the surface during the reentry flight. A comparison of the pressure coefficients between the flight test and the plasma flow analysis at altitudes of 65.8 and $51.5 \mathrm{~km}$ are shown in Figs. 6(a) and 6(b), respectively. In this study, the pressure coefficient, $C_{p}$, was calculated by

$$
C_{p}=\frac{p-p_{\infty}}{\frac{1}{2} \rho_{\infty} U_{\infty}^{2}},
$$

where $p, p_{\infty}, \rho_{\infty}$, and $U_{\infty}$ are the surface pressure, the freestream pressure, the freestream density, and the freestream velocity, respectively.

The computed pressure coefficients are in agreement with the measured data, although there are slight differences near the stagnation point. This comparison indicates that the plasma flow model can feasibly reproduce the flow field around the ESA ARD.

From Figs. 6(a) and 6(b), the peak pressure coefficients in the front heat shield were approximately 1.9 at all altitudes considered herein. The pressure coefficient values exceeding 


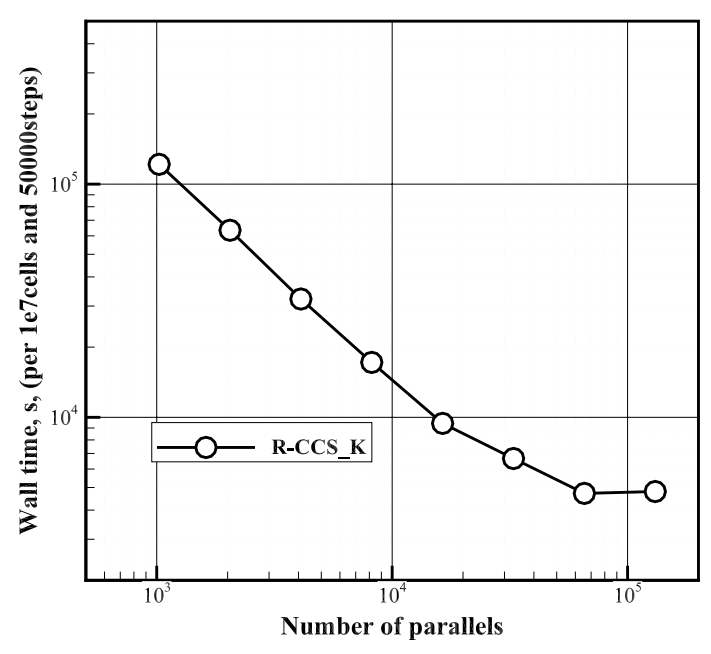

Figure 5: Wall time profile of plasma flow simulations (RG-FaSTAR) for parallel computation using the K computer.

1.0 were mainly due to the compressible effect at the hypersonic regime. However, the pressure rapidly became low in the wake region. This implied that the aerodynamic drag is mostly determined by the front pressure distribution for this type of reentry vehicle. In the wake, the flow field became rarefied, which led to it being a strongly thermochemical, nonequilibrium state of a gas.

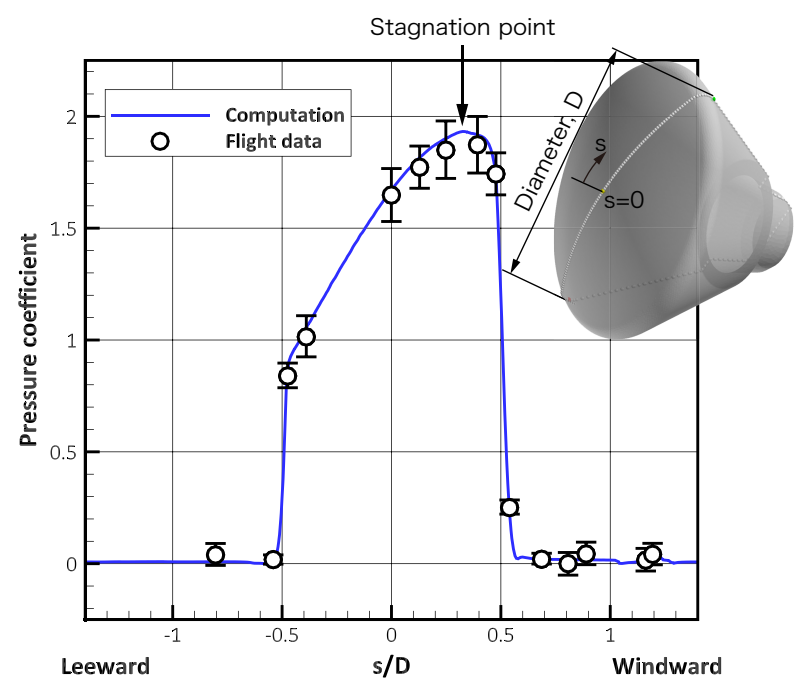

(a) Altitude of $65.8 \mathrm{~km}$.

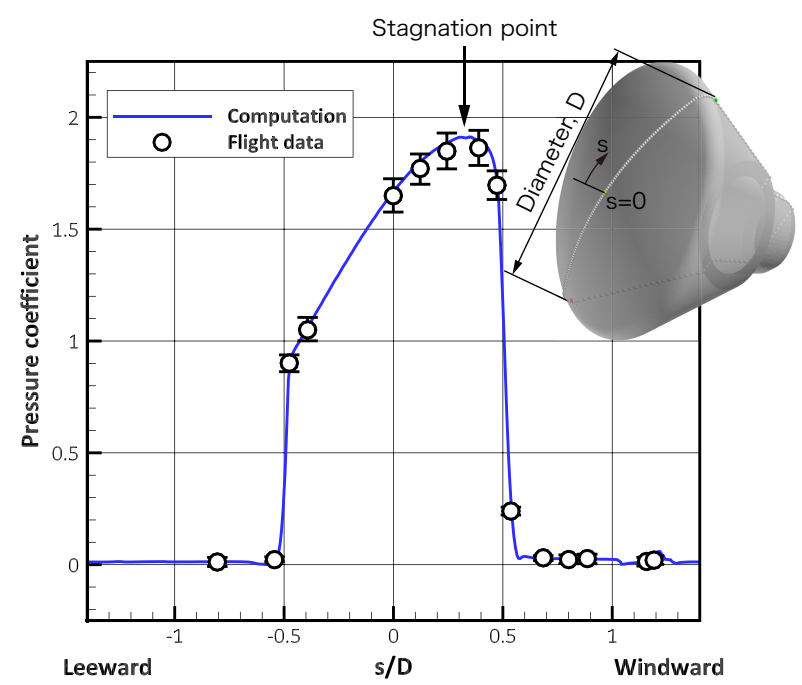

(b) Altitude of $51.5 \mathrm{~km}$.

Figure 6: Comparison of pressure coefficients at different altitudes on the surface of ESA ARD. 


\subsection{Plasma Flow in Shock Layer}

Almost all of the electrons and ionic species around a reentry vehicle are generated in the strong shock layer formed in the front of the vehicle. The reentry vehicle is surrounded by these species advecting and diffusing from the shock layer into the rear part. Although a portion of the electrons and ionic species dissipate through recombination reactions in this flow process, plasma density around the reentry vehicle strongly depends on these electron and ionic species generated in the shock layer. Figures $7(\mathrm{a})$ and $7(\mathrm{~b})$ shows temperatures profiles along the stagnation lines at altitudes of $80.0 \mathrm{~km}$ and $65.8 \mathrm{~km}$, respectively. These figures compare computational results for the non-catalytic wall $(\gamma=0)$ and the fully catalytic wall cases $(\gamma=1)$. In addition, Figs. 8(a) and $8(\mathrm{~b})$ shows the mole fraction profiles at altitudes of $80.0 \mathrm{~km}$ and $65.8 \mathrm{~km}$.

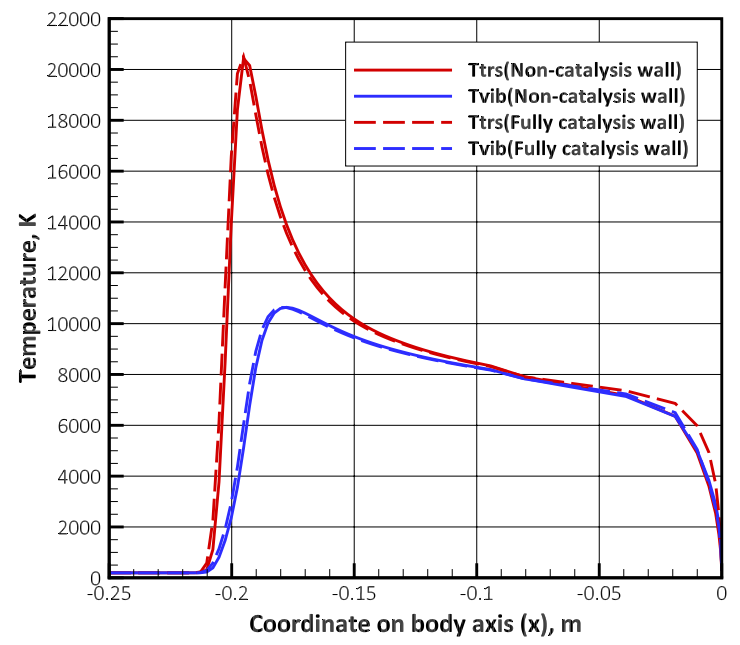

(a) Altitude of $80.0 \mathrm{~km}$.

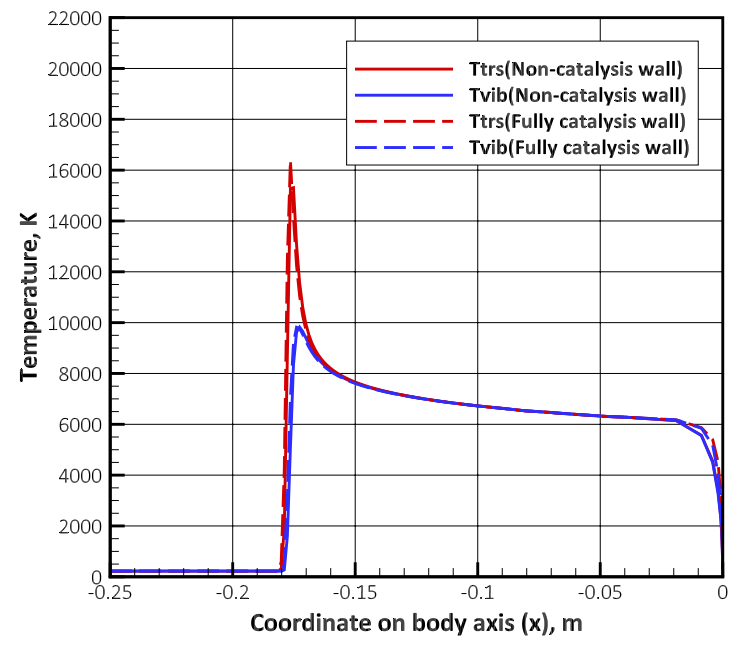

(b) Altitude of $65.8 \mathrm{~km}$.

Figure 7: Temperature profiles along the stagnation line of ESA ARD.

At a higher altitude, the temperatures were perfectly separated into the translationrotation and the vibration-electron temperatures. There appeared to be a strong nonequilibrium state in the plasma flows across the shock wave. However, at a lower altitude, the differences between the two temperature profiles near the shock wave were minimized. In the shock layer, equilibrium regions were observed at these two altitude cases. This was because collisions between chemical species are frequent in high-density regions behind the shock wave, which leads to an increase in energy transfers between translation-rotation and vibration-electron energy modes.

At an altitude of $80.0 \mathrm{~km}$, the dissociation reactions of $\mathrm{N}_{2}$ and $\mathrm{O}_{2}$ across the shock wave proceeded at a slower rate. However, the reactions were rapid for an altitude of $65.8 \mathrm{~km}$. In the equilibrium region, $\mathrm{O}_{2}$ was mostly dissociated, while $\mathrm{N}_{2}$ was partially dissociated. This was attributed to the difference in dissociation energies of each molecule. The dominant chemical species in the shock layer were $\mathrm{N}, \mathrm{O}$, and $\mathrm{N}_{2}$, and the secondary species was NO. The mole fraction of the generated electrons and ionic species, such as $\mathrm{N}^{+}, \mathrm{O}^{+}$, and $\mathrm{NO}^{+}$ was on the order of $10^{-3}$.

It is evident from the comparisons made between mole fractions and temperature profiles that the effects of surface catalysis had a significant impact on the behaviors of $\mathrm{N}$ and $\mathrm{O}$ 


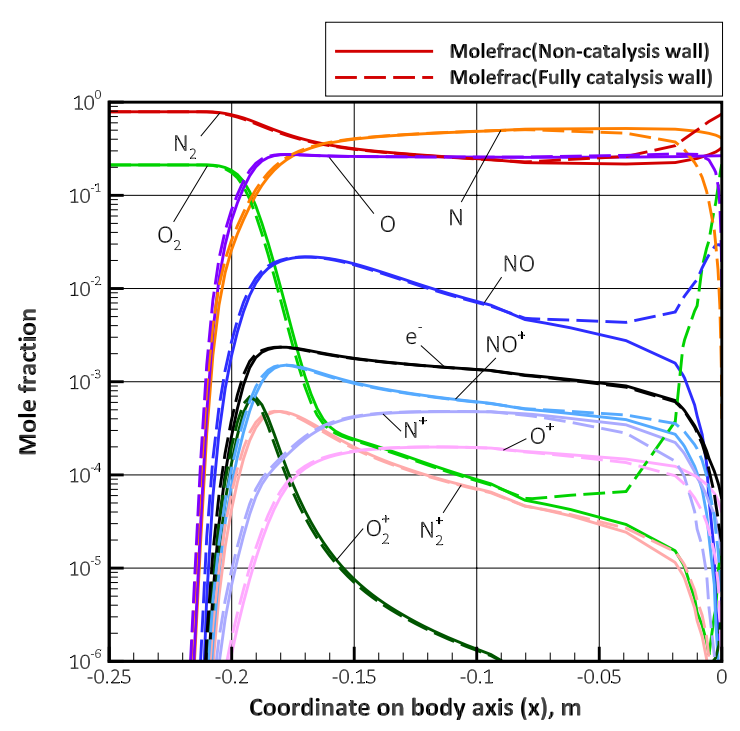

(a) Altitude of $80.0 \mathrm{~km}$.

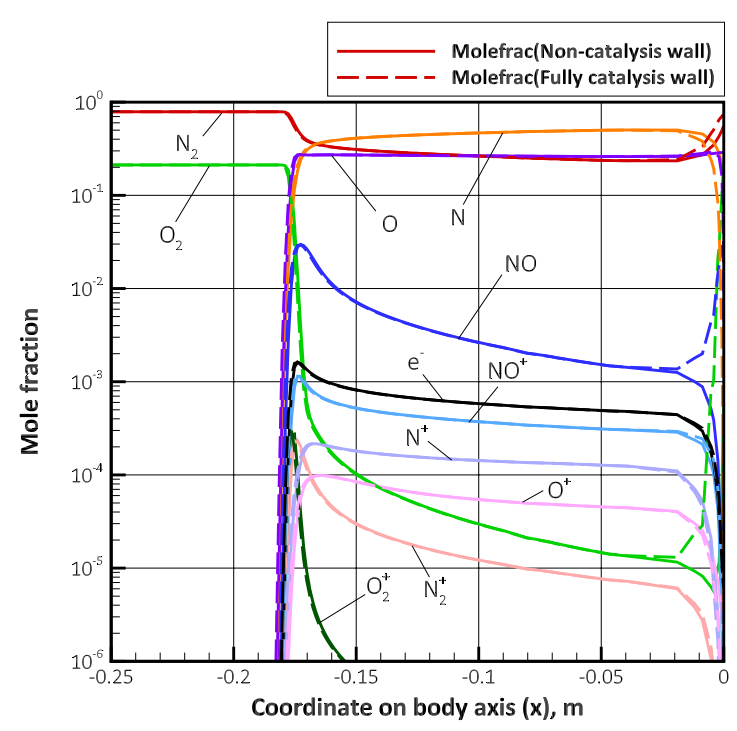

(b) Altitude of $65.8 \mathrm{~km}$.

Figure 8: Mole fraction profiles along the stagnation line of ESA ARD.

near the surface. However, the effects were minor for the temperature profile. For the case of the fully catalytic surface condition, atomic species such as $\mathrm{N}$ and $\mathrm{O}$ were recombined, and thereafter, these molecules were formed near the surface. The chemical species NO increased near the surface for the fully catalysis condition, because the forward reactions of the NO exchange, which are expressed by $\mathrm{N}+\mathrm{O}_{2} \rightleftharpoons \mathrm{NO}+\mathrm{O}$ and $\mathrm{O}+\mathrm{N}_{2} \rightleftharpoons \mathrm{NO}+\mathrm{N}$, promoted $\mathrm{NO}$ as $\mathrm{N}_{2}$ and $\mathrm{O}_{2}$ were increased by the surface catalysis. However, the surface catalysis had an only minor impact on the number of electrons for both altitudes.

\subsection{Wake Flow Behavior}

The surface catalysis can affect formations of chemical species in the wake region of ESA ARD. Figure 9 shows the streamtraces and distribution of velocity in the $x$-direction around the ESA ARD at an altitude of $80.0 \mathrm{~km}$ for the non-catalytic case. Flows passing near the front surface separated with vortices forming at the rear followed by recirculation regions forming as part of the wake flow. Because the flows near the front surface were affected by the surface catalysis, as mentioned above, its influence continued to the wake region. In particular, the low flow velocity in the recirculation region increased the transit time in the region. In this situation, the chemical reactions of the gases were expected to sufficiently proceed in the wake; the chemical component in the region approaches the equilibrium.

Figure 10 shows the distributions of the mole fraction of $\mathrm{N}$ around the ESA ARD at altitudes of 80,70 , and $60 \mathrm{~km}$. In this figure, computed results for cases of non-catalytic and fully catalytic surfaces are compared at each altitude. The results indicate that the degree of dissociation is relatively high at a higher altitude and low at a lower altitude, due to the difference of freestream velocity. Compared to the results of the non-catalysis case, $\mathrm{N}$ notably decreased in the wake region for the cases of fully catalysis. This trend was similar to the distribution of $\mathrm{O}$ around the reentry vehicle, although the figure is not shown here. As mentioned above, flows passing near the surface, which are strongly affected by the surface catalysis, formed the recirculation region at the rear. This extends the influence of surface catalysis to the wake region. 


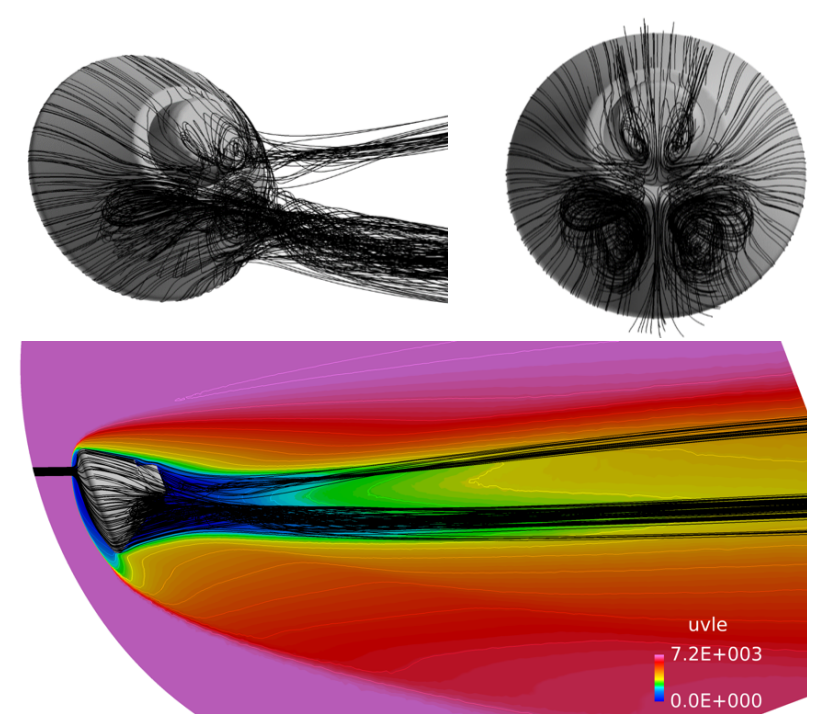

Figure 9: Streamtraces overlapped distribution of velocity in $x$-direction around ESA ARD at an altitude of $80.0 \mathrm{~km}$ for the non-catalytic case.

\subsection{Electron Number Density}

If the plasma is sufficiently thick, electromagnetic waves with a frequency lower than a critical value are completely reflected by the plasma layer. The critical plasma frequency $f_{\mathrm{p}}$ is given by

$$
f_{\mathrm{p}}=\frac{1}{2 \pi} \sqrt{\frac{e^{2} n_{\mathrm{e}}}{\varepsilon_{0} m_{\mathrm{e}}}},
$$

where $e, n_{\mathrm{e}}, \varepsilon_{0}$ and $m_{\mathrm{e}}$ are the elementary charge, the electron number density, the permittivity in free space, and the mass of the electron, respectively. Thus, it is important to evaluate the distribution of the electron number density to investigate RF blackout. In this study, the link frequency is assumed to be $2.267 \mathrm{GHz}$. Therefore, from Eq. 5, the critical electron number density is $6.4 \times 10^{16} 1 / \mathrm{m}^{3}$. When the electron number density of the plasma covering above the antenna of the vehicle is greater than this critical number density, the RF blackout can occur.

Figure 11 shows the distributions of the electron number density around the ESA ARD at altitudes between 85.0 and $51.5 \mathrm{~km}$. Results for the cases of non-catalysis and full-catalysis are also compared for each altitude in the figure. The maximum value of the legend of the figure corresponds to the critical number density.

The electron number densities at the front of the vehicle exceeded the critical value for all altitudes. Thus, the electromagnetic waves cannot propagate in the front direction. However, the wake regions were relatively less dense, due to supersonic expansion, and the electromagnetic waves could propagate in the rear direction. In the wake region, the electron number density tended to increase again, due to the recompression shock formed at the rear of the vehicle. At an altitude of $85.0 \mathrm{~km}$, for the non-catalytic case, the surface of the ESA ADR was covered by a dense plasma layer. In this situation, the electromagnetic waves cannot be emitted from the antenna on the vehicle surface.

At an altitude of $70.0 \mathrm{~km}$, the ESA ARD was completely surrounded by a plasma exceeding the critical number density for both the non-catalysis and full-catalysis cases. Similar 


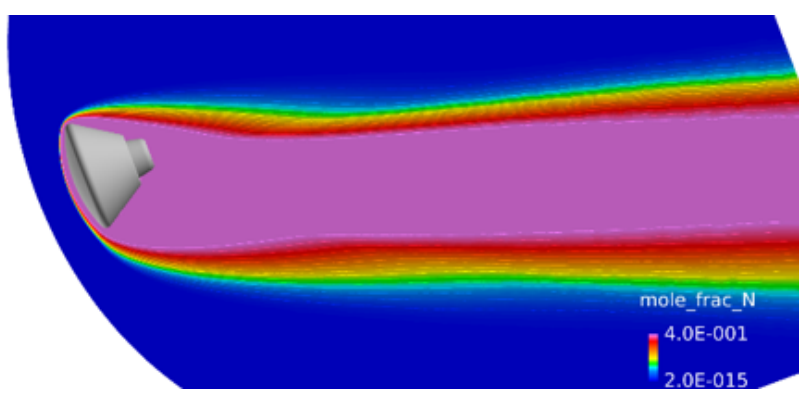

(a) Altitude of $80.0 \mathrm{~km}$ for non-catalytic case.

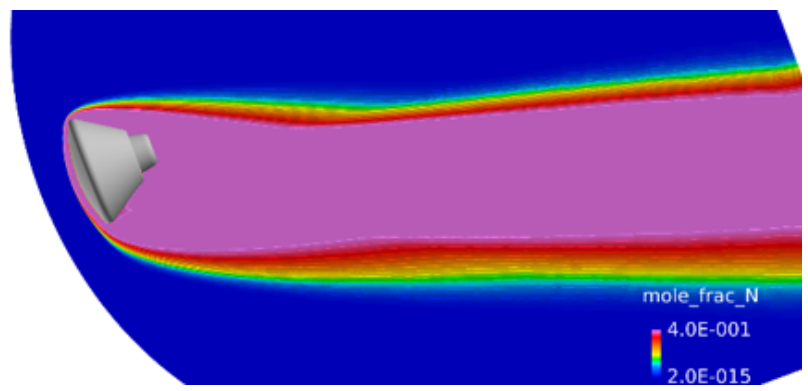

(c) Altitude of $70.0 \mathrm{~km}$ for non-catalytic case.

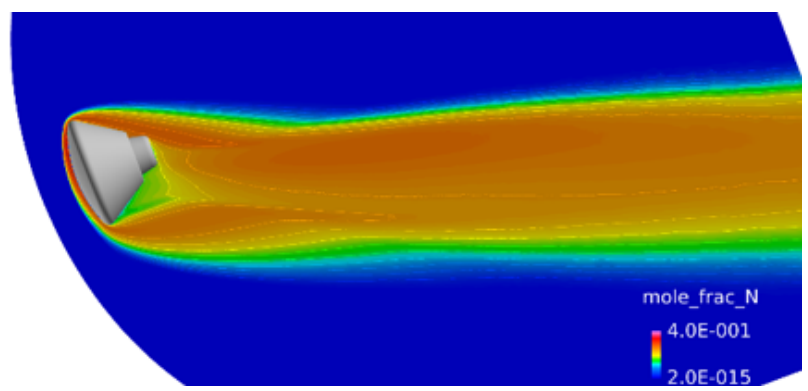

(e) Altitude of $60.0 \mathrm{~km}$ for non-catalytic case.

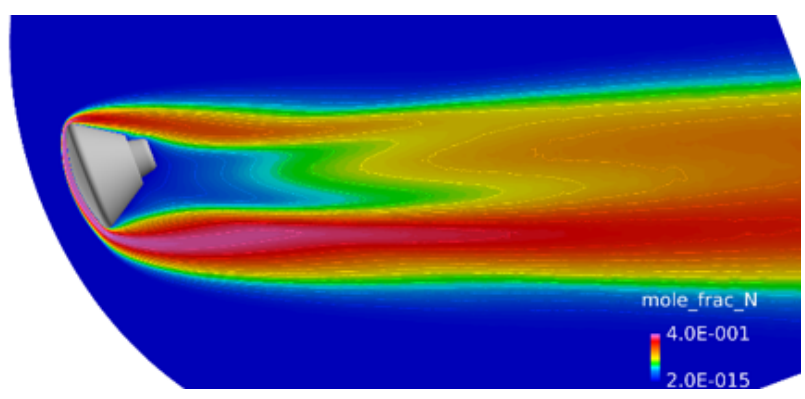

(b) Altitude of $80.0 \mathrm{~km}$ for fully catalytic case.

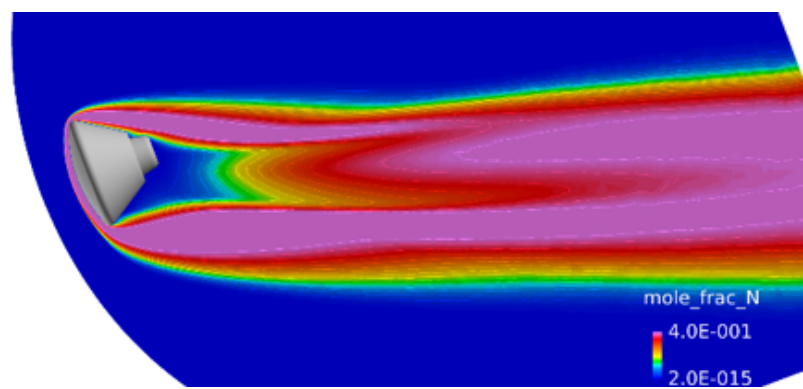

(d) Altitude of $70.0 \mathrm{~km}$ for fully-catalytic case.

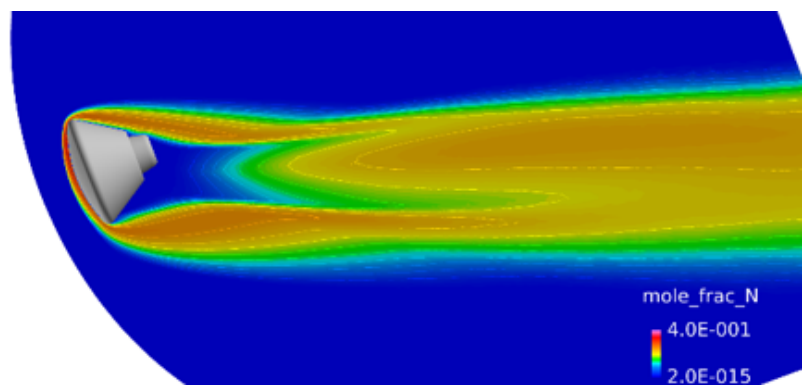

(f) Altitude of $60.0 \mathrm{~km}$ for fully-catalytic case.

Figure 10: Distributions of the mole fraction of N around the ESA ARD at different altitudes. Non-catalytic cases are displayed on the left side and fully-catalytic cases are displayed on the right side.

to the cases at an altitude of $70.0 \mathrm{~km}$, the ESA ARD was surrounded by a critical number density plasma at altitudes of 75.0 and $65.0 \mathrm{~km}$, although the corresponding figures are not presented here. This is not directly related to the surface catalysis effects. At a higher altitude, the low freestream density led to a low electron number density. However, at a lower altitude, the plasma density in the rear decreases owing to rapid recombination reactions. This is caused by a higher freestream density, which causes the flow to attain a high chemical equilibrium. In addition, a decrease in the reentry velocity enhanced this tendency.

The surface catalytic effects on the electron number density were observed clearly in the wake, including the recirculation region. At altitudes of $85.0,80.0,60.0$, and $51.5 \mathrm{~km}$, the plasma densities reduced and the wake paths, where the electromagnetic waves sufficiently propagate, were formed at the rear of the ESA ARD. However, at altitudes between 75.0 and $65.8 \mathrm{~km}$, owing to high freestream velocities and densities, numerous electrons are generated in the shock layer. As the ESA ARD is surrounded by high density electrons, the wake path for communications could not be formed. Despite this, a slight decrease in the electron number was observed near the rear of the ESA ARD. Due to surface catalysis, $\mathrm{N}_{2}$ and $\mathrm{O}_{2}$ were generated in the wake region as $\mathrm{N}$ and $\mathrm{O}$ were dissipated. When the molecules increased 

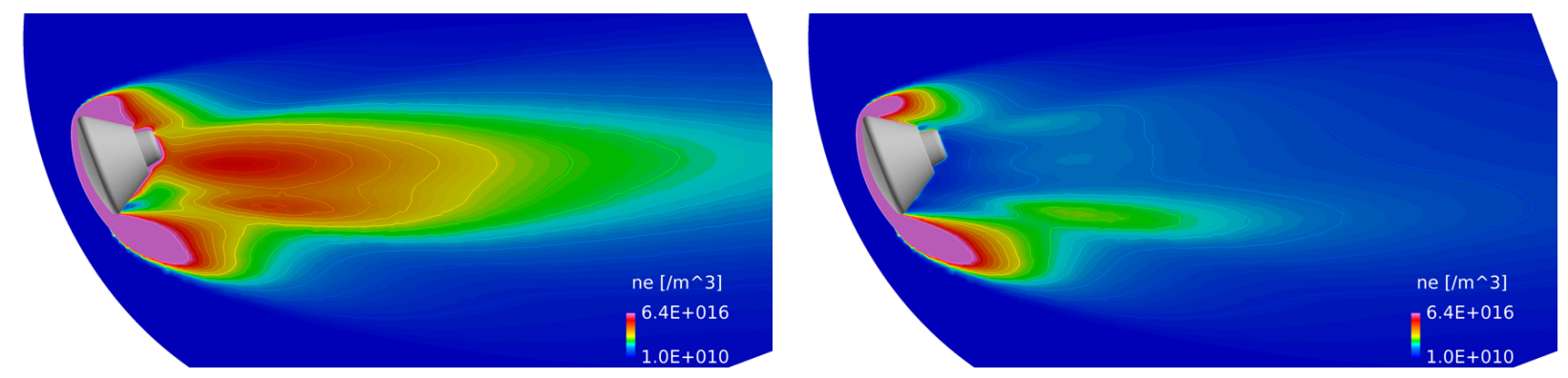

(a) Altitude of $85.0 \mathrm{~km}$ for non-catalytic case $(\gamma=0)$. (b) Altitude of $85.0 \mathrm{~km}$ for fully-catalytic case $(\gamma=1)$.
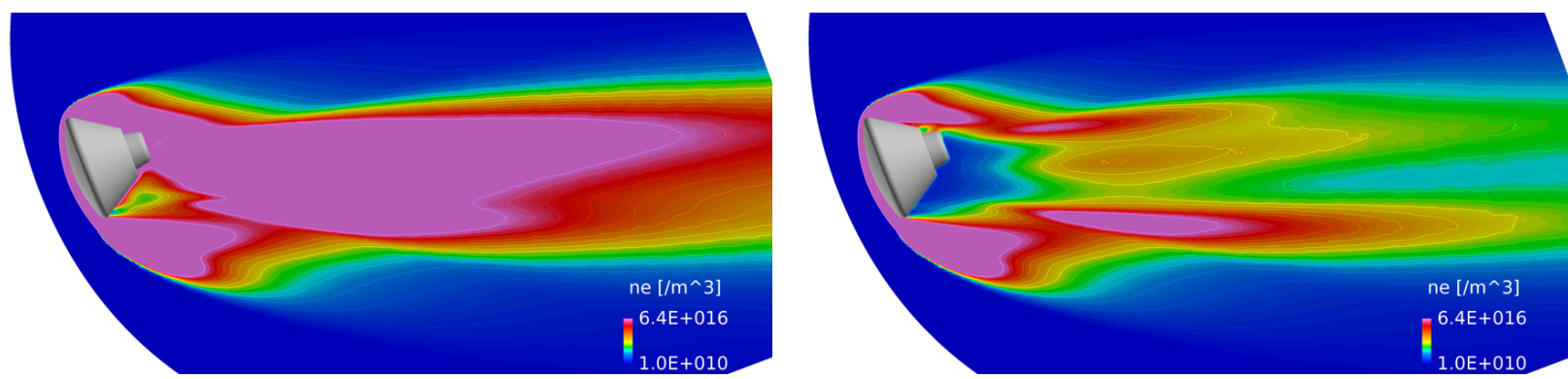

(c) Altitude of $80.0 \mathrm{~km}$ for non-catalytic case $(\gamma=0)$.

(d) Altitude of $80.0 \mathrm{~km}$ for fully-catalytic case $(\gamma=1)$.
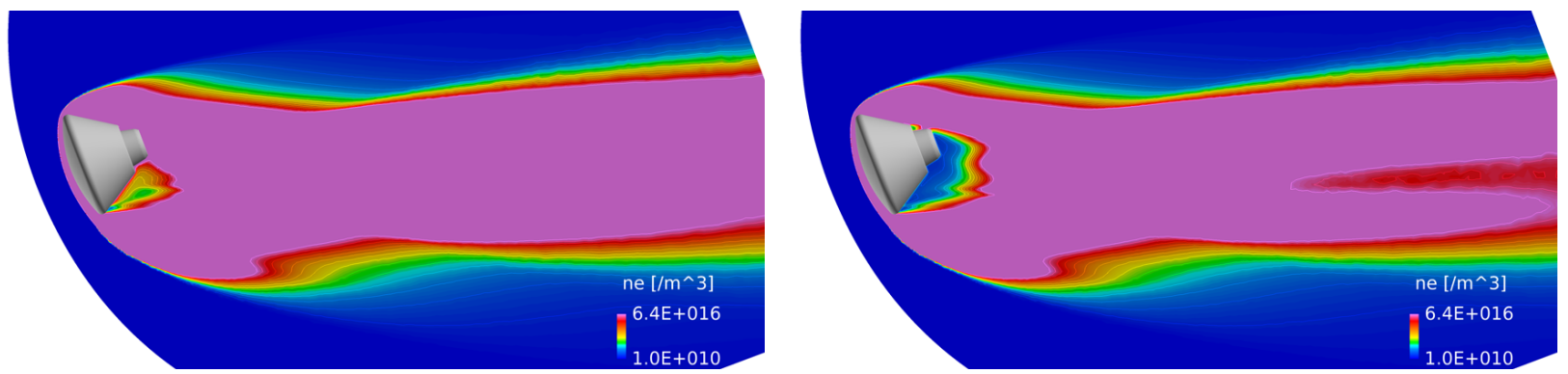

(e) Altitude of $70.0 \mathrm{~km}$ for non-catalytic case $(\gamma=0)$.

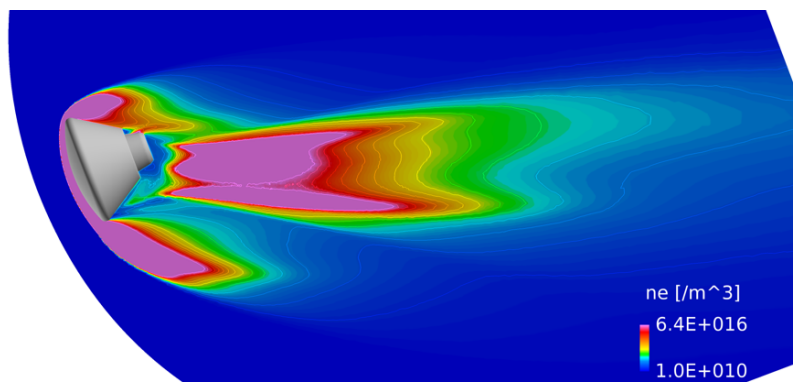

(f) Altitude of $70.0 \mathrm{~km}$ for fully-catalytic case $(\gamma=1)$.

(g) Altitude of $60.0 \mathrm{~km}$ for non-catalytic case $(\gamma=0)$.
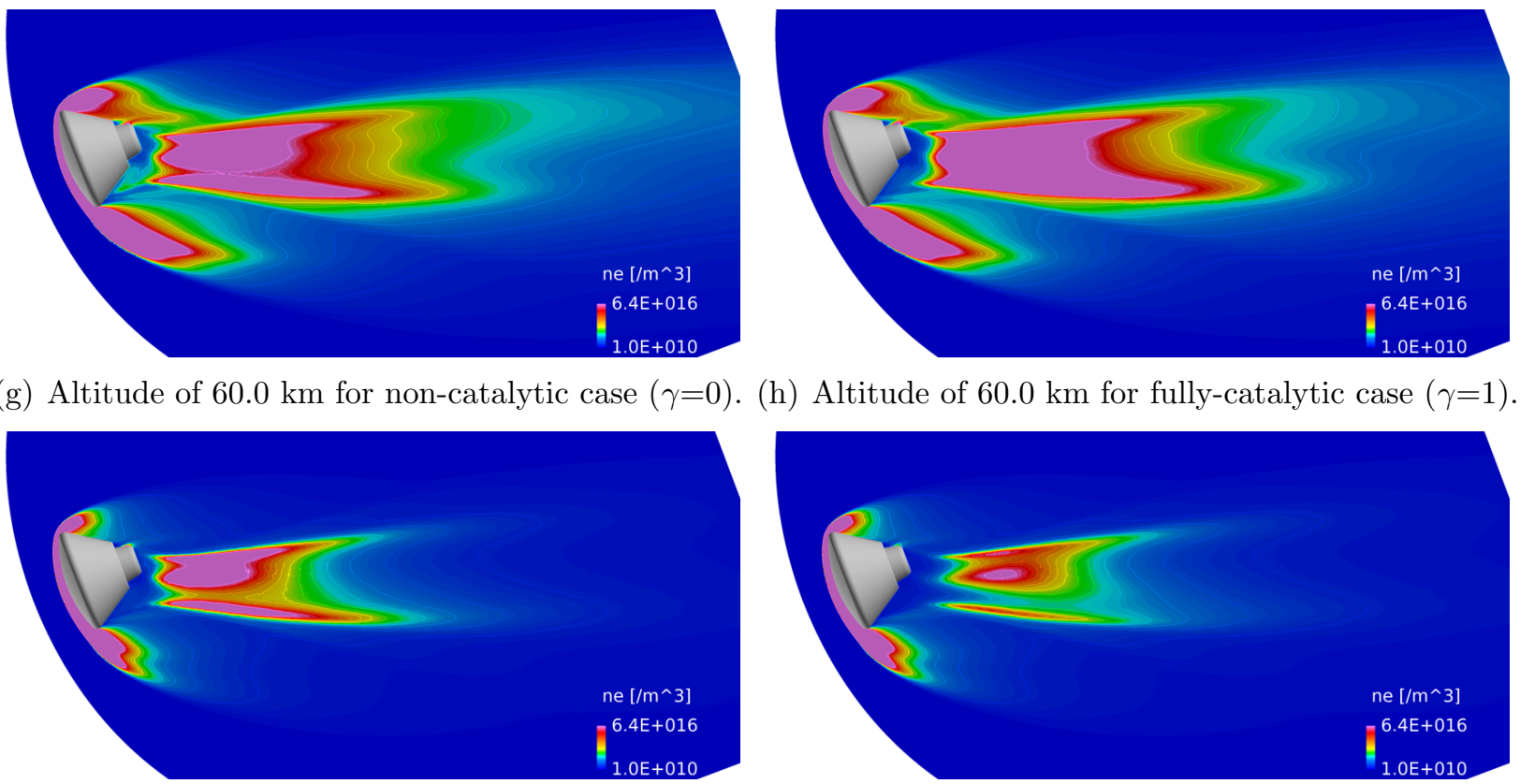

(i) Altitude of $51.5 \mathrm{~km}$ for non-catalytic case $(\gamma=0)$. (j) Altitude of $51.5 \mathrm{~km}$ for fully-catalytic case $(\gamma=1)$.

Figure 11: Distributions of electron number density around the ESA ARD at different altitudes. Non-catalytic cases are displayed on the left side and fully-catalytic cases are displayed on the right side. 
and the atomic species decreased, the backward reactions of the electron-impact ionizations were enhanced, expressed by

$$
\begin{aligned}
& \mathrm{N}+\mathrm{e}^{-} \rightleftharpoons \mathrm{N}^{+}+\mathrm{e}^{-}+\mathrm{e}^{-}, \\
& \mathrm{O}+\mathrm{e}^{-} \rightleftharpoons \mathrm{O}^{+}+\mathrm{e}^{-}+\mathrm{e}^{-} .
\end{aligned}
$$

Because the transit time in the wake increased for the species involved with these reactions, the reactions tended to proceed by the recirculation region. For these reasons, the electrons in the wake decrease, despite the electrons near the front surface hardly changing, due to the surface catalysis. The electrons did, however, increase in the recompression shock for a fully-catalytic case, at an altitude of $60 \mathrm{~km}$. By the surface catalysis, NO was also generated by the NO exchange reactions. This led to the generation of $\mathrm{NO}^{+}$and electrons via the associative ionization reaction and the dissociation of NO in the recirculation region. However, this situation requires the condition of many molecules in the recirculation region and high chemical equilibrium. Thus, the increase in electrons in the recompression shock was observed only at limited altitudes.

In the present model for analyzing plasma flows, the laminar flow assumption was introduced while the Reynolds number at a lower altitude was of the order of $10^{5}$. In contrast, at a lower altitude where the Reynolds number increases, the blackout tends to decrease owing to a decrease in the electron density. The turbulence is expected to have only a small influence on the RF blackout problem. In addition, the accuracy and reliability of turbulent models, including a large eddy simulation approach at the hypersonic regime, are ongoing issues that have hitherto been insufficiently resolved. With regard to conducting more detailed simulations, these concerns remain as issues that need to be addressed in the future.

\subsection{Electromagnetic Waves}

Propagation behaviors of the electromagnetic waves for telecommunications between the ESA ARD and TDRS were numerically investigated based on the computed results of plasma flows. Figures 12(a) and 12(b) shows the electric field distributions of the electromagnetic waves around the ESA ARD at an altitude of $85.0 \mathrm{~km}$, for low catalytic and fully catalytic cases. The distributions display the magnitudes of the electric field vector, which are described in the logarithmic scale. The antenna for telecommunications was installed at the rear surface of the ESA ARD. The magnitude of the electric field on the antenna was normalized to 1.0 in the present calculations.

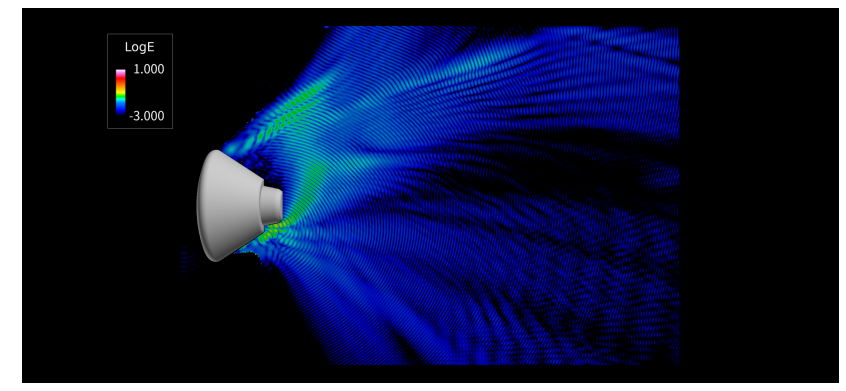

(a) Low catalytic case $(\gamma=0.05)$.

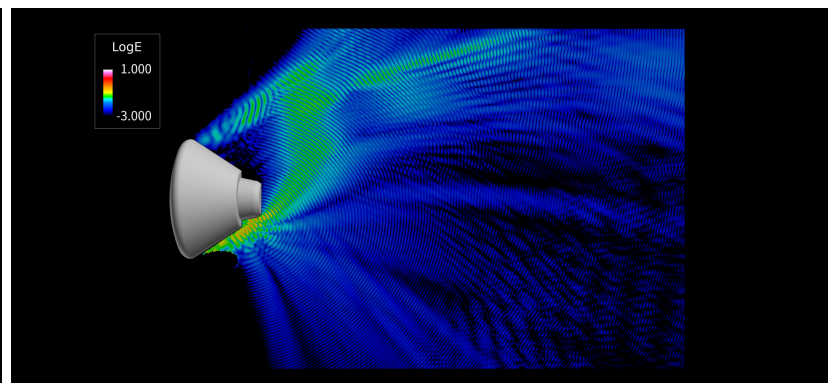

(b) Fully catalytic case $(\gamma=1)$.

Figure 12: Distributions of the electric field magnitude of electromagnetic waves around the ESA ARD at an altitude of $85.0 \mathrm{~km}$. 
For both cases, the electromagnetic waves emitted from the antenna were reflected and absorbed in the high-dense plasma in front of the ESA ARD. Therefore, the electromagnetic waves could not propagate in the front direction. However, the waves propagated into the rear region, where the electron number density was sufficiently low. Due to reflection and diffraction on the front shock layer and the vehicle surface, the electromagnetic waves exhibited complicated behavior around the ESA ARD. These trends were similar for most altitudes, excluding those between 75.0 and $65.8 \mathrm{~km}$, where the RF blackout occurred. For the fully-catalytic case, the electric field in the wake path region was enhanced, in comparison to the non-catalytic case. The results show that the propagation of the electromagnetic waves was improved by the surface catalysis effect.

To evaluate the influence of the surface catalysis on plasma attenuation of the electromagnetic waves, the plasma attenuation gains were compared with the computed results for the low and full catalysis cases and the measurement data obtained in the ESA ARD flight. For the calculations, the plasma attenuation gain is obtained by the following expression:

$$
G_{\mathrm{PA}}=10 \log \left(\frac{|\mathbf{E}|^{2}}{\left|\mathbf{E}_{\mathrm{fs}}\right|^{2}}\right),
$$

where $\mathbf{E}$ and $\mathbf{E}_{\mathrm{fs}}$ are the electric field vectors of the electromagnetic waves for telecommunication with the TDRS propagating in the plasma and free space, respectively. To evaluate $\mathbf{E}_{\mathrm{fs}}$, a simulation of the electromagnetic wave propagation around the ESA ARD located in free space was individually performed. The electric fields in Eq. (8) are obtained for windows on the far-field boundary in which the TDRS is visible at each altitude; the electric fields were obtained in the same manner as that outlined in previous studies [8,27]. Figure 13 shows a comparison of the plasma attenuation gains between the flight test and the computed results. The measured plasma attenuation gain, "Flight_data" in the figure, was obtained by TDRS in the ARD flight mission [9]. The computed results exhibit gains for the electromagnetic waves attenuated by the presence of plasma around the ESA ARD for the low-catalysis and full-catalysis cases.

The plasma gain was improved for the full-catalysis case, in comparison to the lowcatalysis case. This was notably observed at a higher altitude where the flow field around the ESA ARD is in thermochemical nonequilibrium. The computations indicated that the plasma attenuation gain became infinitesimally low at altitudes between 75.0 and $65.8 \mathrm{~km}$ for both the low-catalysis and full-catalysis cases, i.e., at the time of the RF blackout. However, the flight measurement data showed that the RF blackout did not occur for telecommunication with the TDRS, although strong attenuation was confirmed. As highlighted by Jung et al. [28], this may be due to chemical reaction models used in the computations. The associative ionization reactions, such as $\mathrm{N}+\mathrm{N} \rightleftharpoons \mathrm{N}_{2}^{+}+\mathrm{e}^{-}$, have a significant impact on the formation of electrons and ionic species at this altitude range. The reaction models of the associative ionization used herein include relatively large uncertainties, which led to the overestimation of the generation of electrons in the simulation. However, this issue is independent of the surface catalysis effects. This is one of the future issues of ionization reaction modeling to be improved upon for electromagnetic wave predictions.

\section{Conclusions}

We numerically investigated surface catalysis effects on the radio frequency blackout for a vehicle in an orbital reentry mission. Electromagnetic wave propagation in reentry plasma 


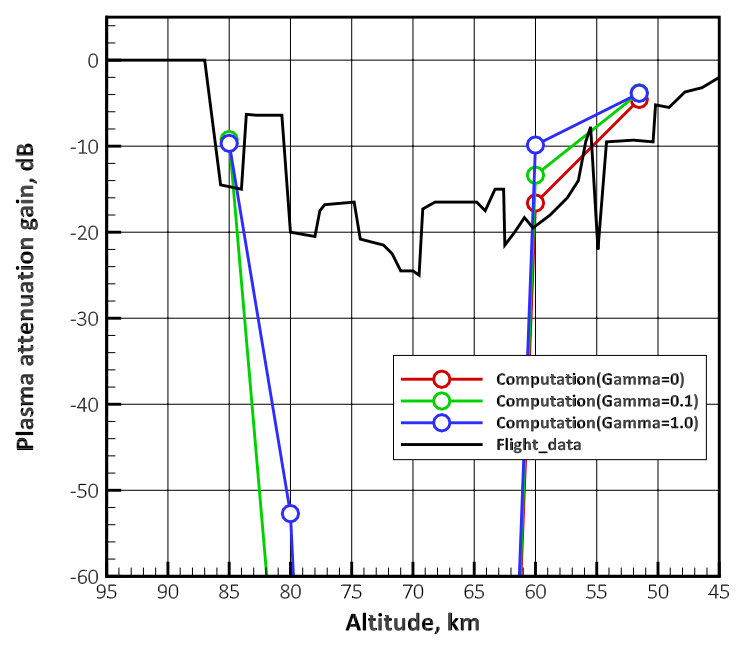

Figure 13: Comparison of plasma attenuation gains between the ESA ARD flight test and the computed results, with regard to low and full catalysis.

was reproduced using a computational fluid dynamics coupled with the frequency-dependent finite-difference time-domain method. Since this required a large computational resource, the Riken center for computational science K computer, which is one of the largest computers, was used. The good scalability of the computations under massive parallelization was confirmed. In addition, the computational models were validated against the measured data of the reentry vehicle.

The computed results regarding the low and full surface catalysis boundary conditions, imposed on the vehicle surface, were compared. Atomic nitrogen and oxygen, dissociated in a shock layer formed in the vehicle's front, were recombined by the surface catalysis. A large number of the recombined molecules flowed into the wake region of the vehicle. However, the surface catalysis itself had almost no influence on the dissipation of electrons in the shock layer. The molecules caused backward ionization reactions, i.e., recombinations of electrons, which led to a decrease in the electron number density in the wake region. The decrease in the electrons formed propagation paths for the electromagnetic waves in the wake of the reentry vehicle. From the above reasons, mitigation of the RF blackout in reentry plasma by surface catalysis was numerically demonstrated.

In general, surface catalysis results in an increase in aerodynamic heating, which is one of the most significant problems during atmospheric reentry. Thus, a compromise between the $\mathrm{RF}$ blackout mitigation and aerodynamic heating should be considered in the engineering design of reentry vehicles. In this study, the surface catalysis effects were numerically investigated but an experimental demonstration was not performed. To reliably confirm the effects, investigations using plasma generators, such as arc-heated wind tunnels, will be considered for the future.

\section{Acknowledgments}

This work was supported by JSPS KAKENHI grant numbers $17 \mathrm{~K} 14871$ and 17KK0123. The presented computational results were obtained using the fast unstructured CFD code 
"FaSTAR", which was developed by JAXA. This research used computational resources of the K computer provided by the RIKEN Center for Computational Science through the HPCI System Research project (Project ID: hp170041, hp180024, and hp190033).

\section{References}

[1] J.P. Rybak and R.J. Churchill. "Progress in Reentry Communications". IEEE Transctions on Aerospace and Electorinic System, 7(5):879-894, September 1971.

[2] L.C. Schroeder and F.P. Russo. "Flight Investigation and Analysis of Alleviation of Communications Blackout by Water Injection during Gemini 3 Reentry". NASA TM $X$-1521, pages 1-56, 1968.

[3] H. Usui, H. Matsumoto, F. Yamashita, M. Yamane, and S. Takenaka. "Computer Experiments on Radio Blackout of a Reentry Vehicle". In D.L. Cooke, editor, Proceedings of 6th Spacecraft Charging Technology Conference, AFRL-VS-TR-20001578, pages 107110. Eurpean Space Agency, the NASA Astrophysics Data System, September 2000.

[4] M. Kim, M. Keidar, and I.D. Boyd. "Analysis of an Electromagnetic Mitigation Scheme for Reetnry Telemetry Through Plasma". Journal of Spacecraft and Rockets, 45(6):12231229, November-December 2008.

[5] I.F. Belov, V.Y. Borovoy, V.A. Gorelov, A.Y. Kireev, A.S. Korolev, and E.A. Stepanov. "Investigation of remote antenna assembly for radio communication with reentry vehicle". Journal of Spacecraft and Rockets, 38(2):249-256, 2001.

[6] Y. Takahashi, K. Yamada, and T. Abe. "Examination of Radio Frequency Blackout for an Inflatable Vehicle during Atmospheric Reentry". Journal of Spacecraft and Rockets, 51(2):430-441, March 2014.

[7] M. Jung, H. Kihara, K.i. Abe, and Y. Takahashi. "Numerical simulation of plasma flows and radio-frequency blackout in atmospheric reentry demonstrator mission". AIAA Paper 2017-3308, 2017.

[8] Y. Takahashi. "Advanced validation of CFD-FDTD combined method using highly applicable solver for reentry blackout prediction". Journal of Physics D: Applied Physics, 49(1):015201, 2016.

[9] P. Tran, J.C. Paulat, and P. Boukhobza. "Re-entry Flight Experiments Lessons Learned - The Atmospheric Reentry Demonstrator ARD". Nato Report, RTO-EN-AVT-130-10, pages 10-1 - 10-46, June 2007.

[10] A. Hashimoto, K. Murakami, T. Aoyama, K. Ishiko, M. Hishida, M. Sakashita, and P.R. Lahur. "Toward the Fastest Unstructured CFD". AIAA Paper 2012-1075, 2012.

[11] C. Park. "Assessment of a Two-Temperature Kinetic Model for Dissociating and Weakly Ionizing Nitrogen". Journal of Thermophysics and Heat Transfer, 2(1):8-16, Jan.-March 1988.

[12] C. Park. Nonequilibrium Hypersonic Aerothermodynamics. Wiley, New York, 1990. 
[13] R.N. Gupta, J.M. Yos, R.A. Thompson, and K.P. Lee. "A Review of Reaction Rates and Thermodynamic and Transport Properties for an 11-Species Air Model for Chemical and Thermal Nonequilibrium Calculations to 30000 K". NASA RP-1232, Aug. 1990.

[14] J.M. Yos. "Transport Properties of Nitrogen, Hydrogen Oxygen and Air to 30,000 K". TRAD-TM-63-7, Research and Advanced Development Division, AVCO Corp., 1963.

[15] J.O. Hirschfelder, C.F. Curtiss, and R.B. Bird. Molecular Theory of Gases and Liquids. Wiley, New York, 1954.

[16] M. Fertig, A. Dohr, and H.H. Frühaufu. "Transport Coefficients for High-Temperature Nonequilibrium Air Flows". AIAA Paper 98-2937, 1998.

[17] M. Fertig, A. Dohr, and H.H. Frühauf. "Transport Coefficients for High-Temperature Nonequilibrium Air Flows". Journal of Thermophysics and Heat Transfer, 15(2):148156, April-June 2001.

[18] C.F. Curtiss and J.O. Hirschfelder. "Transport Properties of Multicomponent Gas Mixture". Journal of Chemical Physics, 17(6):550-555, June 1949.

[19] K. Kitamura and E. Shima. "Towards shock-stable and accurate hypersonic heating computations: A new pressure flux for AUSM-family schemes". Journal of Computational Physics, 245:62-83, 2013.

[20] A. Jameson and S. Yoon. "Lower-Upper Implicit Schemes with Multiple Grids for the Euler Equations". AIAA Journal, 25(7):929-935, July 1987.

[21] T.R.A. Bussing and E.M. Murman. "Finite-Volume Method for the Calculation of Compressible Chemically Reacting Flows". AIAA Journal, 26(9):1070-1078, 1988.

[22] J. Shang and E. Josyula. "Numerical simulations of non-equilibrium hypersonic flow past blunt bodies". In 26th Aerospace Sciences Meeting, page 512.

[23] K. Peery and S. Imlay. "Blunt-body flow simulations". In 24th Joint Propulsion Conference, page 2904, 1988.

[24] K.S. Kunz and R.J. Luebbers. The Finite Difference Time Domain Method for Electromagnetics. CRC Press, Boca Raton, 1993.

[25] K.S. Yee. "Numerical Solution of Initial Boundary Value Problems Involving Maxwell's Equation Isotropic Media". IEEE Transactions on Antennas and Propagation, 14(3):302-307, 1966.

[26] G. Mur. "Absorbing Boundary Conditions for the Finite-Difference Approximation of the Time-Domain Electromagnetic-Field Equations". IEEE Transactions on Electromagnetic Compatibility, EMC-23(4):377-382, 1981.

[27] Y. Takahashi, K. Yamada, and T. Abe. "Prediction Performance of Blackout and Plasma Attenuation in Atmospheric Reentry Demonstrator Mission". Journal of Spacecraft and Rockets, 51(6):1954-1964, Novermber 2014.

[28] M. Jung, H. Kihara, K.i. Abe, and Y. Takahashi. "Reentry blackout prediction for atmospheric reentry demonstrator mission considering uncertainty in chemical reaction rate model". Physics of Plasmas, 25(1):013507, 2018. 